\title{
THE OXFORD HANDBOOK OF
}

\section{COMPUTER MUSIC}

Edited by

ROGER T. DEAN 


\title{
OXFORD \\ UNIVERSITY PRESS
}

Oxford University Press, Inc., publishes works that further Oxford University's objective of excellence

in research, scholarship, and education.

\author{
Oxford New York \\ Auckland Cape Town Dar es Salaam Hong Kong Karachi \\ Kuala Lumpur Madrid Melbourne Mexico City Nairobi \\ New Delhi Shanghai Taipei Toronto
}

With offices in

Argentina Austria Brazil Chile Czech Republic France Greece Guatemala Hungary Italy Japan Poland Portugal Singapore South Korea Switzerland Thailand Turkey Ukraine Vietnam

Copyright $\odot 2009$ by Oxford University Press, Inc.

First published as an Oxford University Press paperback $20 \mathrm{II}$

Published by Oxford University Press, Inc.

198 Madison Avenue, New York, New York Ioor 6

www.oup.com

Oxford is a registered trademark of Oxford University Press

All rights reserved. No part of this publication may be reproduced, stored in a retrieval system, or transmitted, in any form or by any means, electronic, mechanical, phorocopying, recording, or otherwise, without the prior permission of Oxford University Press.

Library of Congress Cataloging-in-Publication Data

The Oxford handbook of computer music/ edited by Roger T. Dean.

p. $\mathrm{cm}$.

Includes bibliographical references and index.

ISBN 978-o-t 9-979203-o (alk. paper)

1. Computer music-History and criticism. I. Dean, R. T.

MT $>80.092009$

2.2008046594

\subsection{OXF b/11}




\section{SENSOR-BASED} MUSICAL

\section{INSTRUMENTS AND INTERACTIVE MUSIC}

\section{A TAU TANAKA}

Musicians, composers, and instrument builders have been fascinated by the expressive potential of electrical and electronic technologies since the advent of electricity itself. Musical applications have accompanied, and often driven, developments in magnetic and electrical field effects, the transistor revolution, digital representation, and more recently advanced sensing and mobile technologies. Scientific progress has given rise to entire movements and styles in music-magnetic recording giving birth to musique concrète and electroacoustic music, radio broadcast technology inspiring the field of radio art and hörspiel, and the transistor being the key component in synthesizers that catalyzed the birth of electronic music. These developments are considered in a chronology in the appendix to this volume. The synthesizer, followed by the digital sampler, gave rise to a new family of musical instruments. Early experiments to validate these inventions as true musical instruments consisted of testing their ability to imitate the timbral richness of acoustic instruments. Ironically, while the expressive fidelity of electronic imitations continued to be criticized, their convenience often resulted in these new instruments replacing traditional orchestral instrument performers in commercial recordings. At the same time, electrical and 
electronics technologies were applied to enhance, then extend, traditional instruments. The emblematic example of this is the electric guitar. Magnetic coil transducer technology was applied first to amplify an acoustic guitar. The arrival with Leo Fender of the solid-body electric guitar gave rise to a guitar with little acoustical properties, its sound being uniquely identified by associated amplification technology. A technology of extension resulted in the creation of an entirely new instrument, spurring on the development of major movements in popular music.

This chapter pinpoints a specific movement within this broad spectrum of music technology to identify a musical and instrument-building tradition concerned with gesture. This area of research and creative practice, often labeled NIME after the international conference series New Interfaces for Musical Expression, goes beyond enhancing traditional instrument performance practice to looking at new paradigms for instrumental performance. At the same time, the focus remains on establishing the notion of an instrument and applying the metaphor to new technologies. In this way, NIME does not consider the sociological impact of technology on musical authorship, distribution, and consumption. There is also a wealth of etudes and sketches that look at musical instruments from an industrial design perspective, which falls beyond the scope of this chapter.

This text instead focuses on musically driven efforts to exploit analog and digital technologies to capture musical gesture and afford new forms of sonic articulation and musical expression. These new instruments permit the live performance of electronic and digital music by capturing different kinds of performer gesture, be they free-space movement, action on an interface, or geographical displacement. From a musical point of view, the field draws on traditions of instrument design, instrument building, and subsequent composition/improvisation for and performance on the instrument. From a research perspective, it is a domain informed by related fields of real-time technologies and human-computer interaction. Not surprisingly, the NIME conference, as the leading professional meeting in the field, historically arose out of the more generalist conference on Computer Human Interaction (CHI), a special interest group of the Association for Computing Machinery (ACM).

The founding of NIME in 2001 represented the historical culmination of what until that point was a disparate field of practice. This text retraces the history of music technology in the 2oth century that led up to the founding of NIME and introduces composers and performers who have established a performance practice on interactive, sensor-based musical instruments. The chapter finishes by indicating current directions in the field, including the musical exploitation of biometric signals and location-tracking technologies.

\section{Historical Movements}

The advent of electricity had a profound impact on the imagination of musicians. This was due in no small part to the fact that sound played such an integral part in 
these early developments. The telegraph used a series of audible pulses to communicate text. Later, the telephone carried audio directly from one location to another. Radio allowed sound to be transmitted over wireless links, and wire recording captured and stored audio for later playback. Each of these inventions operated on the notion of transduction-the process of converting a physical phenomenon to and from an electrical signal, allowing physical variations to traverse different media and span distance and time. It would only be later that image could be manipulated electrically in this way. Photography is the chemical impregnation of image, and even film only uses electricity indirectly to illuminate a series of photographic images. Sound, on the other hand, accompanied electricity as the first medium to be transduced and transmitted on electrical wires.

This close coupling between audio and electricity gave rise to new forms of creative musical expression, including radio art and electronic music. In the spirit of the time were a group of engineers and musicians worldwide who imagined new musical instruments that leveraged the power of electricity to permit gestural instrumental performance of electronic musical sounds.

The most famous of these instruments was the theremin, invented in 1919 by the Russian engineer and amateur musician Leon Theremin. The theremin consisted of electrical circuitry powering two antennas in an orthogonal arrangement. The antennas generated and detected perturbations in the electrostatic field around the instrument. By moving one's hands in the zone around the antennas, the performer affected the electrostatic fields, changing the sound produced by the instrument. The theremin's circuitry was configured so that the horizontal antenna affected the amplitude of the resulting sound, and the vertical antenna affected the frequency, or pitch, of the sound. The timbre was a fixed periodic waveform that could be adjusted by auxiliary controls. In this way, the theremin used the metaphor of a traditional musical instrument like the violin, with one gesture controlling the pitch and another articulating the volume of sound. Like the violin, the tonal range was continuous in that there were no indicators (or frets) quantizing the frequency output to specific notes of the musical scale. While on the violin there was contact with physical materials-bowing of the string and pressing of the string on the fingerboard, gestures on the theremin took place in free space in front of the instrument.

The theremin was not the only instrument produced in this early era of electrical exploration. In France, the Ondes Martenot was invented in 1928 by Maurice Martenot and was successfully integrated in orchestral ensembles of the time, with works by composers such as Arthur Honegger, Olivier Messiaen, and Edgard Varèse. Aided by a traditional musical keyboard for pitch selection, articulating sound took place by moving a ring connected to a string in threedimensional space over the keyboard. In Germany, the trautonium was created in 1929 and functioned on a resistive wire in contact with a metal plate. Invented by Friedrich Trautwein, it was developed by and performed on by Oskar Sala, with compositions by Paul Hindemith. In Canada, the inventor Hugh Le Caine created a series of instruments, the best known being the Electronic Sackbut of 1945, 
recognized as the first voltage-controlled synthesizer. Control of volume, pitch, and timbre was realized in three dimensions by means of pressure sensors.

Electronic musical instrument building met the digital era with the work of Max Mathews. Credited as the inventor of digital audio, the process by which analog audio signals are coded as a series of binary numbers, Mathews worked as an engineer and researcher at Bell Laboratories in the 1960s. Alongside his seminal work of that time, notably on the MUSIC family of computer sound synthesis and composition programming languages, Mathews created an instrument called GROOVE (Generated Real-Time Output Operations on Voltage-Controlled Equipment), a hybrid analog-digital system in which a two-dimensional joystick controller modulated electronically generated sound output. The instrument was designed and built in collaboration with the composer and developer, Laurie Spiegel, who would continue the approach with Music Mouse, an early example of Macintosh music software in the 1980 os.

\section{Defining the Instrument}

The focus of the systems described here is the notion of an instrument. As there can be many assumptions on what constitutes a musical instrument, it is useful here to try to define the makeup of a musical instrument and in what ways new technologies and new musical movements extend and challenge these established notions.

Today, the most common definition of a musical instrument is of an acoustical instrument that is a member of the classical orchestra. These instruments can be categorized in instrument families (stringed instruments, woodwind instruments, brass instruments, percussion instruments) and within each family can be subdivided into instruments based on note range and articulatory means.

This definition of musical instrument goes beyond the classical orchestra to include instruments used in popular and ethnic musics and more recently nonacoustical instruments such as the synthesizer. In all cases, it is implied that the musical instrument is a self-contained and autonomous sound-producing object that enables a musician to perform in a live situation.

Developments in musical style have extended the use of the word instrument to include new musical devices, at times challenging the very nature of the word. Musique concrète is a studio-based art by which sound is constructed in a painterly way. What was afforded by editing sound as recorded on tape through electronic treatments was to free the composer from the abstraction and detachment of composing on paper and transmitting the work to an instrumentalist. This direct manipulation of the medium was heralded as a revolution in Pierre Schaeffer's manifesto for the field, liberating the composer from the musician. This touches on the politics of creativity that are beyond the scope of this chapter and have been 
discussed elsewhere in this and other volumes. What is relevant to the present discussion is the fact that even in this nonperformative extreme, the term instrument has been used-it has been said that with musique concrète the studio became the instrument of the composer.

In other developments of musical style, the evolution of disc jockey (DJ) from a radio broadcast role to a performer in hip-hop and techno musics has brought with it the development of DJ culture in which the vinyl record turntable has become a musical instrument in its own right. The development of turntablism extends the traditional notion of musical instrument-the turntable is indeed autonomous and self-contained and, in those styles of music, is used to perform in live concert situations. At the same time, the turntable challenges traditional definitions of musical instrument as it relies on prerecorded materials to make sound. It can be argued that in the late zoth century musicians began to work with sound at a higher level of abstraction than that of individual notes and timbres. This coincides with postmodernist notions of appropriation, reproduction, and simulation. What is relevant here is that musicians, regardless of the level of abstraction, seek to be expressive and performative with sound and, to facilitate this musical urge, invent musical instruments.

Beyond the conceptual considerations of turntable-as-musical-instrument, this serves as an illustrative example of the scope of the musical instrument. The turntable is autonomous and self-contained in a way similar to a traditional instrument. However, as an electronic instrument, it needs a speaker system to produce sound. In this way, it is similar to the electric guitar-an electric guitar is incomplete without a guitar amplifier. The choice of amplifier and associated circuitry (be it tube or solid state) and the quality and size of the speakers have an enormous effect on the final sound and ultimately the expressivity of the instrument. The question then arises whether the instrument definition in the case of the electric guitar stops at the guitar itself or expands to include the amplifier and the effects pedals in between?

The turntable adds to this its dependence on vinyl records as source material. While the turntable itself is self-contained, it is ultimately an open-ended system that depends on content played on it. The performance of a DJ depends as much on his choice of records as it does on his performance technique. The very same turntable can be used in a noninstrumental way by a radio DJ or purely for music listening by a consumer in a home hi-fi system. The instrument then depends not only on content, but also on context. Finally, there is the question of configuration, as many turntablists perform with two or even three turntables connected by an audio DJ mixer. The number of turntables used changes the nature of the instrument, as can the choice of DJ mixer, the characteristics of its equalizers and crossfade slider. This raises the question of the scope of the instrument as embracing content, context, and configuration-is the musical instrument in question the turntable itself or the system of turntables, record collection, DJ mixer, and ultimately sound system chosen by the performer? 


\section{Open-Ended Systems}

The view of a musical instrument as an open-ended system comprised of multiple components can be applied to digital technology and becomes a musical perspective from which to broach questions of the "instrumentality" of hardware/software architectures of live computer music performance systems.

Such a system typically consists of the following components:

- Input device-often a sensor and data acquisition subsystem to capture performer gestures

- Mapping algorithms-software subsystem to translate gestural data into musical information

- Sound synthesis engine-real-time audio generation in which sound synthesis parameters are modulated by live input

- Compositional structure-a structural layer defining the musical sections or progression of the work

- Output system-audio output subsystem consisting of output channel configuration and digital-to-analog converters (DAC)

Typical questions that arise include the following: Is the instrument just the sensor hardware, or does it include software components like the mapping and sound synthesis software subsystems? Where does the instrument end and the composition begin? Is the entire system specific for one musical work, or can parts of it (e.g., the synthesis or compositional components) be altered or generalized to create different works for the same instrument? What happens to the boundaries distinguishing traditional roles of instrument builder, composer, and performer?

Confronting these questions from an engineering perspective are rhetorical concerns defining open-ended or closed systems. A musical point of view differentiates the way these questions are confronted. This distinguishes sensor-based musical instrument design as a creative musical pursuit distinct from a purely technical engineering pursuit. In this way, the notion of musical instrument as instrument is distinct from that of a tool.

The term tool implies that an apparatus takes on a specific task, utilitarian in nature, carried out in an efficient manner. A tool can be improved to be more efficient, can take on new features to help realize its task, and can even take on other, new tasks not part of the original design specification. In the ideal case, a tool expands the limits of what it can do. It should be easy to use and be accessible to a wide range of naïve users. Limitations or defaults are seen as aspects that can be improved.

A musical instrument's raison d'etre, on the other hand, is not at all utilitarian. It is not meant to carry out a single defined task as a tool is. Instead, a musical instrument often changes context, withstanding changes of musical style played on it while maintaining its identity. A tool gets better as it attains perfection in realizing its tasks. The evolution of an instrument is less driven by practical 
concerns and is motivated instead by the quality of sound the instrument produces. In this regard, it is not so necessary for an instrument to be perfect as much as it is important for it to display distinguishing characteristics, or "personality." What might be considered imperfections or limitations from the perspective of tool design often contribute to the personality of a musical instrument.

Computers are generalist machines with which software tools are programmed. By itself, a computer is a tabula rasa, full of potential but without specific inherent orientation. Software applications endow the computer with specific capabilities. It is with such a machine that we seek to create instruments with which we can establish a profound musical rapport.

The input device is the gateway through which the user accesses the computer software's functionality. As a generalist device, generalized input devices like the keyboard or mouse allow the manipulation of a variety of different software tools. Music software can be written to give musically specific capabilities to the computer. Input devices can be built to exploit the specific capabilities of this software. On this generalized platform, then, we begin to build a specialized system, each component becoming part of the total instrument description.

In instrumental writing, composing with musical specificity for a target instrument is called idiomatic writing. A music written for a certain instrument should in principle respect and abide by the qualities of that instrument. These qualities include tonal range, techniques of articulation, and facility of performer execution. It is for considerations of idiomatic writing that music for violin differs from music for flute, even if the two instruments share similar tonal ranges. Good instrumental writing should make an instrument "speak" by highlighting its capabilities as well as its limitations. This implies not only staying within the bounds of an instrument, but also pushing the envelope and testing the limits and breaking point of conventional technique.

\section{Controllers}

Interactive musical instrument development in the 1980 s focused on novel controllers. In computing science, this was the era when input devices such as the mouse, trackpad, and tablet became commercially viable. The research in the field of human-computer interaction (HCI) that led up to these developments dealt with enhanced task performance afforded by novel input devices. Input devices such as mice, coupled to advanced graphical user interfaces (GUIs) extended the forms of interaction a computer user could have beyond the classical typewriter keyboard. In a similar way, computer music and electronic music, which had until then relied on the metaphor of the classical piano keyboard as a live input device, sought to leverage the interactive possibilities of new input devices as controllers to allow new forms of musical interaction. 
At the same time, commonly available computing power was still insufficient in the mid-1980s to allow sound synthesis in software on personal desktop computer systems in real time. Digital sound synthesis took place through offline calculations using synthesis and composition languages such as MUSIC V, Csound, and Cmix. Live computer music performance took place on special-purpose synthesis hardware popularized by synthesizers such as the Yamaha $\mathrm{DX}_{7}$ and samplers like the E-mu Emulator II. The arrival of the musical instrument digital interface (MIDI) standard in 1983 allowed the possibility of interoperability across systems-for one keyboard to control another or for a computer-based sequencer to orchestrate a number of synthesizers. This generalized interface bus for interoperation and control became the ideal communications bus for a family of alternate controllers to be developed, both commercially and in the research field.

This spawned a series of electronic musical instrument products that sought to extend the reach of synthesizer performance to nonkeyboard players. Manufacturers such as Yamaha, Akai, and Casio commercialized MIDI controllers based on metaphors of woodwind and brass instruments, using breath pressure sensors and key systems based on wind instrument fingerings that output MIDI note and control data. Guitar-based interfaces were also invented, with hexaphonic pickups detecting the vibration of individual strings on a traditional guitar in the case of the Roland family of guitar synthesizers or using the form factor and physiognomy of a guitar in a completely virtual setup as in the case of the Stepp, SynthAxe, and Yamaha systems.

Some systems went beyond the traditional musical instrument metaphor to imagine new forms of gestural interaction with synthesized sound. The D-beam used infrared distance sensing to capture hand gesture in front of an instrument to create MIDI continuous control data output. The system was later licensed by Roland and integrated as an auxiliary control on synthesizers, much in the way that Moog had in the analog era integrated continuous ribbon controllers above its keyboards. The Sound-beam system continues to be used as a dedicated controller for music therapy applications, and the technique of distance sensing has been generalized and is a common component in instrument systems described in this chapter.

Musicians were captivated by the expressive possibilities of novel interfaces and created custom MIDI controllers. Jean Michel Jarre used Bernard Szajner's Laserharp was a system that used a series of light beams in a vertical array; interruption of the beams by the performer's hands triggered sounds. Serge de Laubier and Remy Dury created the Meta-Instrument, a seated elbow and lower arm prosthesis that used multidimensional joints to translate limb articulation with fifty-four degrees of freedom to control sound synthesis parameters. De Laubier has continued development of the Meta-instrument to be a standing system controlling real-time software sound synthesis and computer graphics. Dury has adapted some of the input technology from the Meta-instrument to an advanced woodwind controller, the KRL.

Mathews continued the research questions he started with GROOVE in creating the Radio Baton, a multidimensional percussion surface. The system consists of two batons and a rectangular surface. The batons are wired to microradio transmitters, 
each transmitting on a separate frequency. The percussion surface serves as matrix antenna, defining zones that could report the $x, y$, and $z$ coordinates of baton position. The MIDI output from the hardware was coupled to step sequencer software, allowing different musical compositions to be performed from the Radio Baton. Typical mappings included tempo beating on one baton stepping through the notes of the composition, and $x-y$ and $z$ position of the two batons modulating expressive sound synthesis parameters. For Mathews, the Radio Baton as musical instrument consisted of the hardware and composition playback software. Other musicians, notably Andrew Schloss and Richard Boulanger, took the hardware as instrument and programmed their own software programs to create different musical compositions.

\section{Hyperinstruments}

While inventing new instruments is the primary pursuit of interactive music, traditional instruments remain an important foundation and serve as springboards for ideas. Established performance practice on existing instruments serves as an important point of reference and source of metaphors for many sensor instruments. Meanwhile, the accumulated history of performance technique on existing instruments gives a richness of musical interaction that serves as a gold standard for evaluating new instruments developed with interactive technologies. History provides a temporal dimension to the tradition of musical instrument development that is not typically associated with the accelerated nature of technology development. Musical instruments evolve out of a synergistic relationship between developments in musical style and material craftsmanship. Digital media, on the other hand, evolve based on engineering advances, an unstoppable technological progress independent of whether the end user has demonstrated a need, with the next level of advancement in format or capacity coming before the previous has been fully explored or assimilated. In music, this means that hardware and software are updated before the musician has had time to create profound musical relationships with a stable system.

Extensions to existing instruments have been a rich area for the musical application of sensor technology. The term hyperinstrument was used by American composer Tod Machover as follows:

The hyperinstrument project was started in 1986 with the goal of designing expanded musical instruments, using technology to give extra power and finesse to virtuosic performers. Such hyperinstruments were designed to augment guitars and keyboards, percussion and strings, and even conducting... The research focus of all this work is on designing computer systems (sensors, signal processing, and software) that measure and interpret human expression and feeling, as well as on exploring the appropriate modalities and innovative content. (http://opera. media.mit.edu/projects/hyperinstruments.html) 
At IRCAM (Institut de Recherche et Coordination Acoustique/Musique), the MIDI Flute was created for use in Boulez's Explosante-Fixe. Alongside the large research-lab-driven efforts are equally important musician-oriented projects in which a composer or a performer develops a single instrument in a highly personal evolution. Frances-Marie Uitti is a virtuoso cellist who has concentrated on contemporary music and has developed extended technique on the violoncello, notably with the use of two bows simultaneously. Part of her innovations in cello performance has been the development of a hypercello, a traditional cello extended with sensors. The instrument was developed in a long collaboration with the Studio for Electro-Instrumental Music (STEIM) in Amsterdam and with musicians and composers, including Joel Ryan. She continues development of the instrument, creating a six-stringed electric cello with interactive electronics in collaboration with David Wessel and Adrian Freed at the Center for New Music and Audio Technologies (CNMAT) of the University of California at Berkeley.

Sarah Nicolls similarly explores extensions to the modern piano. She has commissioned a series of works from composers, including Richard Barrett and Michael Edwards, for piano extended by electronics, and from this has distilled a kind of musical technical specification for a sensor-based piano with which she can perform a body of work. She has built a standing grand piano that allows her to perform prepared piano articulations inside from an upright standing position. Sensors on the pianist's body activate motors and actuators on the piano. In her case, sensing electronics are placed not only on the piano itself but also on the performer's limbs - shoulders, arms, and hands. Here, limits of the instrument go beyond the physical instrument to include electronics on the performer's body.

Nicolas Collins is a composer who has taken the tinkering and hacking aesthetic of the do-it-yourself (DIY) school to create a series of idiosyncratic musical devices. One of his long-standing projects has been an instrument based on a traditional trombone, the "trombone-propelled electronics." The traditional instrument is used as a platform for creating an entirely new instrument-Collins, unlike Nicolls and Uitti, is not a virtuoso on his instrument, and his instrument does not extend traditional performance practice on the instrument. Instead, it uses articulations from trombone performance-breath pressure, slide manipulation-to modulate electronic processes on an outboard signal processor.

\section{Studio for Electro-Instrumental Music}

Studios for electroacoustic music composition and production have often played pivotal roles in the development of technology-based music. This rich tradition includes the Köln studio, IRCAM (Institut de Recherche et Coordination Acoustique/Musique), EMS (Electronic Music Studios), and CCRMA (Center for Computer Research in Music and the Arts). In the area of sensors and music, the studio that has been the leading center in the field is STEIM in Amsterdam. It was founded in 1968 by a collective of composers, including Misha Mengelberg, Louis Andriessen, and Dick Raaijmakers. It was with the arrival of the late Michel 
Waisvisz in 1973 that STEIM took on an instrument-building workshop approach, first producing the Cracklebox, an instrument by which the performer becomes part of the electrical circuitry of the instrument through touch and human conductivity.

The output of the STEIM workshop includes hardware interfaces, programming languages for interaction mapping, and real-time sound and image manipulation software. With these systems, instrument builders have built a family of instruments and artists have realized a diverse range of projects. The Sensorlab was a high-quality sensor interface designed and built by Peter Cost in the mid-1980s. Spider was a programming language by Tom Demeyer with which mapping algorithms were deployed on the Sensorlab hardware. Johan den Biggelaar and Bert Bongers built The Hands, for which Frank Balde programmed performance software. This became the instrument used by Waisvisz for over two decades.

These instruments were at once idiosyncratic instruments highly personalized to a particular artist's needs and at the same time general platforms for groups of artists to explore and extend. Edwin van der Heide took the MIDI Controller, an early version of The Hands, and adapted it for his own solo performances, duos with instrumentalists, and ensemble work with Sensorband. Other configurations of sensors connected to the Sensorlab gave rise to different instruments. A series of stretch sensors connecting strings resembling a spider's web became The Web.

In 1994, Laetitia Sonami worked with Bongers to extend a series of glove interfaces she had previously produced to create an instrument called the Lady's Glove. Bend sensors, Hall effect proximity sensors, and force-sensing resistors (FSRs) were sewn on a Lycra glove and connected to a Sensorlab. With this, Sonami created a musical instrument that allowed movement without spatial reference and with an embodied approach to computer music.

\section{Sensor Interfaces}

The period in the late 1980 s and 1990 s represented a rich period in gestural computer music. Real-time systems began to be portable. Advances in the MIDI specification brought forth the aforementioned alternate controllers by commercial instrument companies. Advances in microelectronics democratized sensor interface device production. Originally, such interfaces, which converted analog control voltage output of sensors to digital data, were the fruit of specialized design efforts at early studios dedicated to the field, such as STEIM or the Institute of Sonology. Even after the popularization of interactive music, input devices were expensive exotic devices, as evidenced by IRCAM's AtomicPro. By the early 2000 s, however, PIC (programmable integrated circuit) and FGPA (field-programmable gate array) technology allowed inexpensive, one-chip solutions to multichannel data acquisition. This resulted in low-cost artist systems such as Infusion Systems' 
I-Cube, Making Things, and Phidgets, ultimately leading to grassroots open source hardware plans for kits exemplified by the Arduino and Mu-IO. Sensors followed a similar path, integrating sensing and signal preprocessing into single-chip solutions that output preconditioned calibrated voltages from acceleration, magnetic fields, gyroscopic rotation, temperature, and other physical effects. This has led ultimately to the introduction of mass-market consumer devices that incorporate sensors such as ultrasound, and accelerometers.

In the research arena, these developments of increasingly convenient sensing and faster computer processing speeds resulted in systems combining musical modalities. SenSAs and Bubbas, produced at Princeton University by Dan Truman and Perry Cook combined spherical speaker systems with sensor input to create self-contained electronic instruments with sound radiation properties allowing better integration in ensembles with acoustical instruments. CNMAT created the Rimas box as a sensor interface sampling at audio sampling rates, allowing gestural control to be treated in the same signal-processing chains as the audio synthesis. At Newcastle University's Culture Lab, Kazuhiro Jo has created low-cost DIY circuitry to preprocess sensor signals to be able to use audio analog-to-digital convertors (ADC) as data input channels in the Inaudible Computing project.

\section{Audio as Sensor}

While sensors can be used to capture performer gesture to extend an instrument's musical palette, the actual sound output of an instrument can be a rich source of information about performer expressivity. The sound of an acoustical instrument, then, can be thought of as data to be "sensed" and analyzed. In this light, a microphone becomes sensor. This builds on the rich traditions of electroacoustic music created for instrument and electronics, making audio itself as the source of interaction. Sophisticated audio effects and signal processing, commonly used in all styles of music, consists for the most part of electronic sonic treatments. With audio sensing, information about musical gesture is extracted from the signal and mapped to sound synthesis parameters. The use of microphone as sensor creates a closed feedback loop and holistic interactive control dynamic. The application of mapping techniques distinguishes the use of microphone as interactive sensor from simple effects.

This approach has been used widely at IRCAM by composers Philippe Manoury and Kaija Saariaho, paralleling and mutually influencing the development of the Max/MSP (Max Signal Processing) software. Fundamental to the development of this now industry standard system, composers Cort Lippe and Zack Settel were fundamentally involved in the development of Max/MSP, creating signal analysis/ resynthesis modules specifically for a body of instrumental compositions. Lippe's "Music for Clarinet and ISPW," and Settel's "Hok Pwah" for voice and percussion 
and "Taudrium" for contrabass are emblematic of this microphone-as-sensor approach.

Ryan has created a veritable musical instrument that is a sophisticated signalprocessing network for acoustical instruments. Performing with virtuosos like saxophonist Evan Parker, the musical instrument definition in this case spans performers and systems, becoming an instrument as ensemble, as meta-system. Ryan takes the microphone-as-sensor instrument notion to its logical extreme by taking the stage and performing alongside the musician whose sound he is treating, creating a duo of instrument and extension of instrument. He has proven the richness of his instrument by using it in a multitude of different musical contexts, styles, and situations.

\section{Virtual Reality Systems}

The development of glove-based instruments paralleled developments in the late 1980 s and early 1990 of of VR technology. The VR systems brought novel input and display systems such as glove interfaces, bodysuits, and head-mounted stereoscopic video displays (HMDs) to create immersive audiovisual environments. This sparked the imagination of artists to create artistic work with these technologies. It also triggered the democratization of sensor technologies in consumer products such as video game controllers. The Nintendo Power Glove, introduced in 1989, while not a commercial success, became a cult device for hacking among artists, who would extend and dismantle it to recover the bend sensors embedded within.

Suguru Goto is a Japanese composer based in France who has worked with VR devices. His "o.m.2-g.i.-p.p." was a sound/image composition for the Body Suit, an instrument that is a full bodysuit armed with sensors, and HMD. The American Joseph Butch Rovan's work with glove controllers includes "Collide," for which subtle finger gestures control sound synthesis and navigation through a series of film noir images.

\section{Tabletop and Surface Instruments}

Developments in the early 2000 s in areas of computer science research such as Computer Supported Cooperative Work (CSCW) and social computing focused on multiuser systems. Tabletop interfaces with multitouch technology allow the tracking of multiple gestures simultaneously on a common surface. Jeff Han's multitouch tabletop created at New York University is one such device. Proximal interaction techniques and electronically tagged objects are another way to track simultaneous objects for musical control. James Patten's AudioPad, developed at 
the Massachusetts Institute of Technology (MIT) Media Labs is a musical composition and performance interface based on this approach. Computer vision-based tracking of multiple objects and their orientations is another approach to control multiple sound synthesis parameters. The ReacTable, developed by Sergi Jordà and his team at the Music Technology Group in Barcelona is an instrument comprised of several modules. A computer vision system called reacTIVision developed by Martin Kaltenbrunner is a software framework for tracking fiducial markers and for multitouch finger tracking. Modular software synthesis allows live repatching of sound based on object manipulation. Finally, physical objects visually tagged with the markers are placed on a computer camera/projection surface to complete the instrument.

Synthesizer designer and instrument builder Don Buchla used a series of 36 FSRs in a single-user instrument approach to multitouch sensing with Thunder. The instrument in effect creates a span of ribbon controllers on a circular surface in front of the musician. A mapping program interface (STORM) allows any combination of sensor input to create specific MIDI output. Composer and performer Wessel of CNMAT has performed extensively with this tactile instrument.

\section{Free-Space Gesture}

Buchla continued with his exploration of MIDI instruments to capture performer gesture with Lightning. Operating on principles of triangulation of infrared beams, the system consists of two smart wands not dissimilar to those of Mathews' Radio Baton. Here, the wands are equipped with infrared transmitters, and the performer waves them in free space in front of a base unit receiver. The horizontal and vertical movements of the wands are captured independently across a series of zones set by the receiver. Some distance/depth effects are also possible. Firmware in the Lightning allows the musician to determine how sound is articulated as each wand moves within a zone and from zone to zone. Improvising sampling musician Bob Ostertag has performed extensively with Lightning, using it to trigger and modulate samples without a traditional keyboard.

The use of infrared light beams restricts the instrumentalist to a line-of-sight relationship with the base unit, and a coordinate system is anchored to the device. To create a nonreferential spatial system in the way that Sonami conceived, accelerometers offer a more generalized solution. Without an absolute reference, however, accumulated error of successive delta values limits the usefulness of accelerometers in calculating position. Instead, selective filtering of accelerometer data allow its use in calculating tilt and detecting dynamic motion.

Much in the way that the Power Glove in the 1980 s democratized access to VR technology, the Nintendo Wii Remote's arrival in 2006 made free-space sensing available to a wide range of artists in an affordable package. The Wii Remote 
contains a 2-D accelerometer and connects to a host over Bluetooth. Music software on the computer would then receive a stream of serial data representing the motion of the device in three dimensions. This essentially replicates and generalizes specialist systems that had been created by Sonami and others over the years.

\section{Biosignal Instruments}

The idea to interface the intention of the musician, be it physical gesture or musical thought, directly to sound output has fascinated composers for decades. To do so entails creating a musical system based on human physiology. Biofeedback systems have traditionally been the means to look at evoked response. Since then, the notion of biocontrol has been developed. Recently, the area of brain-computer interface has received much attention and has potential in musical applications.

Analog biofeedback systems have been employed in music since the 1960 . David Tudor, composer and collaborator of John Cage, used biofeedback in his signal paths that directly manipulated audio. Alvin Lucier's "Music for Solo Performer" is the seminal work in this area. Lucier wrote: "I realized the value of the EEG [electroencephalogram] situation as a theater element.... I was also touched by the image of the immobile if not paralyzed human being who, by merely changing states of visual attention, can activate ... a large battery of percussion instruments" (Lucier 1995).

David Rosenboom created a family of mixed media biofeedback works and defined the field as follows: 'The term 'biofeedback' will be used herein to refer to the presentation to an organism, through sensory input channels, of information about the state and/or course of change of a biological process in that organism, for the purpose of achieving some measure of regulation or performance control over that process, or simply for the purpose of internal exploration and enhanced selfawareness" (Rosenboom 1976).

The use of EEGs, or the recording of brainwave signals, has fascinated numerous artists and musicians. Since Lucier and Rosenboom's time, advanced multichannel electrode systems allow more detailed monitoring of human brain activity. Meanwhile, low-cost electronics have made notions of biofeedback accessible to a wider range of artists. Interfaces such as the Interactive Brainwave Visual Analyzer (IBVA) of Masahiro Kahata have been used by New York musician Miya Masaoka to extend her instrumental performance practice. As a low-amplitude, high-noise signal, however, extracting meaningful signals from the brain remains a challenge. The use of medical electrode systems has allowed rigorous study of musical intent as expressed in the EEG. The Dutch scientist Peter Desain has studied evoked response in EEG to rhythmic stimuli, examining the possibility of detecting through EEG a subject imagining a rhythm by matching EEG output to recorded 
traces while listening to that rhythm. Developments in the area of brain-computer interfaces (BCIs) have been extended to musical interaction. The Brazilian composer Eduardo Miranda proposes brain-computer music interfaces (BCMIs) in which continuous EEG readings activate generative music algorithms and biosignal complexity modulate musical dynamics. Andrew Brouse has created meditative installation/performances using this technology.

The advent of digital signal-processing techniques in the 1980 s made reproducible control of interaction elements more reliable than with analog techniques. With this came the fundamental shift from artistic use of biofeedback to introducing the notion of biocontrol. While biofeedback allows the physiological state to be monitored and to be translated to other media by means of visualization or sonification, biocontrol seeks to create reproducible volitional interaction using physiological biosignals. Performance artists such as Laurie Anderson and Pamela $Z$ have used the BodySynth of Chris van Raalte and Ed Severinghaus to capture theatrical movement to trigger musical accompaniment to their actions. The BioMuse by R. Benjamin Knapp and Hugh Lusted allowed continuous tracking of brainwaves (EEG), eye movement (electro-oculogram, EOG), and muscle tension (EEG) signals to shape and modulate sound synthesis parameters and musical flow. I have created a body of work and performed extensively with the BioMuse system in solo and group concert settings. Teresa Marrin Nakra of the MIT Media Lab has used Delsys active dry electrode systems in a bodysuit for electromyographic (EMG) tracking of gesture of an orchestral conductor. Yoichi Nagashima has created homemade circuitry pre-dating the DIY movement to replicate EMG-based musical interaction. More recently, Miguel Ortiz Pérez, working at the Sonic Arts Research Centre (SARC) in Belfast with BioMuse inventor Knapp, has used a commercial version of the BioMuse (BioFlex) to analyze muscular gestures in musical performance.

\section{Ensembles}

Ensemble performance is an essential component of musical practice and often creates compelling musical contexts to uncover musical qualities of an instrument. Music, from this point of view, is an inherently social activity-communication dynamics exist between performer and audience, and an interaction dynamic exists between a performer and his or her instrument. Ensemble performance adds a sophistication and complexity to these flows by intermixing human interaction among performers with instrumental interaction of each performer with the performer's instrument. This results in streams of nonverbal communication that are at the heart of musical interaction. Individual human-machine interaction creates a musical whole by becoming the conduit of a collective communicative space. Ensemble situations in this way create critical test cases for the immediate expressivity and context-switching capabilities of an instrument. A successful 
ensemble can also be thought to become a sort of meta-level instrument comprising multiple actors.

Acoustical instruments display a musical flexibility that allows them to traverse a variety of musical contexts and styles. From solo to ensemble, in groups of differing scales from chamber music to bands to orchestras, and for musical styles that may see a single instrument performing folk, popular, symphonic, or avantgarde musics, instruments in the traditional acoustical musical instrument family have developed over the history of music an extraordinary capacity to adapt to different musical contexts.

Do interactive, technology-based musical instruments exhibit a similar level of adaptability? Much in the way that we sought to identify the articulatory potential of an instrument that defined its musical richness, a corollary to this is the ability of an instrument to change musical contexts, to play among other instruments and musically contribute to the whole yet maintain its own sonic identity. Traditional instruments and ensembles have developed this over the course of musical history. To what extent can technology instruments begin to attain this level of complexity and adaptability?

Group performance has been a part of interactive instrument history since the early instruments were introduced. The theremin and Ondes Martenot have figured in symphony orchestras not only as soloists but also as integral parts of the orchestra, motivated in part by the desire to prove their musical adaptability and in a hope to integrate electronic instruments into orchestral tradition. Ensembles consisting only of electronic instruments have also existed, notably a chamber ensemble of Ondes Martenots.

In 1966, the American composer Cage created Variations $V$ for a group of theremin-like antennas. Rather than investigate the expressive depth of chamber music performance, here a 1960 s ethos in "happenings" brought about creating a unique event to see the ways that technology could extend music to occupy space. This aesthetic pioneered by Cage and Tudor, of a group of musicians channeling chance and complexity through live performance, was taken up in the 1980 s by The Hub, a computer network band composed of San Francisco musicians John Bischoff, Tim Perkis, Chris Brown, Scot Gresham-Lancaster, Mark Trayle, and Phil Stone. The work of The Hub is presented in depth elsewhere in this volume. As their name implies, they made use of, at first, homemade network interconnection technology to create a digital music ensemble. In this light, they are the precursors in the field of network music, a field of musical research unto itself described by Álvaro Barbosa and others. For the themes of instrumental performance central to this chapter, it can be said that The Hub created a collective musical instrument out of the very technologies that facilitate being an ensemble.

By the early 1990s, sensor-instrument performance had become active, particularly in the Netherlands, with projects from the Institute of Sonology at the Royal Conservatory of the Hague and at STEIM. From this active scene of experimentation, instrument building, and performance, three musicians, Edwin van der Heide, Zbigniew Karkowski, and I, formed Sensorband, a trio of sensor-based 
instrumentalists. Van der Heide performed on the MIDI Conductor, an early version of what was later to become The Hands used by Waisvisz. Karkowski performed on a scaffolding cage armed with a series of infrared beams, and I performed on the BioMuse EMG interface. This grouping of distinct instruments united by the theme of gestural interaction in a musical group applied the notion of a chamber music ensemble made up of a single instrument family, in this case the family of sensor instruments. Sensorband toured extensively for ten years before disbanding in 2003. I went on to form another trio, Sensors_Sonics_Sights with Laurent Dailleau and Cécile Babiole. Alongside the BioMuse were ultrasound rangers used by Babiole and Dailleau's theremin. This second-generation band is notable for its juxtaposition of historical instruments like the theremin alongside modern biosignal interfaces and the integration of live image manipulation into the instrumental ensemble.

The Hub and Sensorband were early examples of network ensembles and sensor-instrument groups, respectively. They inspired a series of groups, including the German group Tryonis and the Australian group Metraform. However, the number of ensembles dedicated to computer-based instruments remains small. Ensemble performance of interactive instruments with acoustic instruments is more common. Wessel of CNMAT performed throughout the 1990 s with the Buchla Thunder controller in various improvised music contexts, including with trombonist George Lewis and Pakistani vocalist Shafqat Ali Khan. Ryan of STEIM tours extensively with the saxophone virtuoso Parker. The improvised music scene in general assimilated performers on keyboard samplers. From this practice, Ostertag extended this tradition to perform in ensembles with Fred Frith and other notable improvising musicians, using the Buchla Lightning infrared wand controller to articulate and sculpt output from a sampler.

Meanwhile, the rapid miniaturization of computing power that allowed real-time computer music to run on laptop computers created an artists' scene unto itself of laptop music. While other writings comprehensively cover this musical movement, it is interesting to note that ensemble formation also took place in this scene-that is, sensor instruments and gestural articulation were ultimately not a prerequisite for the computer music "band." The Princeton group created the Princeton Laptop Orchestra (Plork). Underground artists in the laptop music scene created all-star lineups, including the laptop orchestra constituted by Mego label manager and musician Pita Rehberg in the early 200os. More stable ensembles emerged from the Japanese scene, including the laptop orchestra organized by Philippe Chatelain and the Sine Wave Orchestra organized by Jo Kazuhiro and colleagues.

If performing on laptop computers facilitated computer use in a musical ensemble, this was taken even further by projects that treated acts of computer programming or electronic circuit building as musical acts that could be set in a group context. Ge Wang created a live performable computer music programming language, ChucK, and with Perry Cook made duo performances of "Co-Audicle" in which the two performers coded from scratch directly onstage, projecting their code onstage in a live setting. Masayuki Akamatsu and students at the International 
Academy of Media Arts and Sciences (IAMAS) created and performed with the Breadboard Band, a musical ensemble that constructed sound-producing electronics circuits on prototyping boards live.

\section{Network Music}

Following the seminal work of The Hub, by the early 2ooos, network-based music applications became a fertile area for exploration of ensemble performance. Most projects looked at the network as a conduit by which to facilitate remote performance of traditional music. Musicians and researchers Chafe, Settel, and Rowe at CCRMA (Stanford), McGill University, and New York University, respectively, used ultra-high-bandwidth Internet 2 infrastructure to demonstrate low-latency ensemble performance of jazz. Elaine Chew has conducted rigorous study of distributed chamber music rehearsal. Recently, remote orchestra conducting has become a practical reality. Synchronization of loop-based systems in commercial sequencer software appeared in the late 1990 s with the ResRocket system, while research systems like PeerSynth and SoundWire have integrated network latency in sound synthesis.

Networks have also become an integral part of the computer music instrument, with remote ensemble performance becoming not a replacement for single-site performance but a distinct mode of play that took on its own musical properties, notably in Jordà's FMOL (Faust Music On Line). The accessible and democratized nature of the Internet resulted in musicians and researchers creating public participation systems that incorporated elements of networked ensemble play in musical activities aimed at the layperson. This resulted in attempts to create commercial software and in public exhibition installation works such as Barbosa's "Public Sound Objects."

\section{Mobile and GPS-Based Instruments}

As musicians looked toward advances in new sensor systems, location tracking in outdoor space by means of the global positioning system (GPS) entered the instrumentarium of composers and artists. While GPS had been available to civilians since the late 1980 s, military scrambling of the signal via selective availability (SA) deliberately reduced distance resolution, making it unuseful for artistic purposes. The opening up of direct non-SA satellite signals to the general populace in the Clinton administration of the late 1990s spawned the boom of consumer satellite navigation systems. This was seized on by artists, who founded the 
Locative Media art movement in the early 200os; direct high-resolution tracing of the geography of human movement became the material of mixed-media artworks. In the music realm, this has borne a family of location-based musical works. The specific temporal requirements of music place advanced demands on GPS technology. This has been articulated through either artistic use of errors in the signal or research efforts that have made contributions to development in technical fields.

While location-tracking techniques such as GPS have inspired and facilitated artists' works, the relationship between urban space and sound pre-dates the arrival of digital technologies. Artists such as Janet Cardiff created the notion of sound walks; a prescribed path through urban space was accompanied by soundscape and narrative. This has spawned a series of commercial applications in the area of audio guides, and the increasing memory capacity of personal music players, networked capabilities of mobile telephones, in conjunction with the location awareness afforded by GPS allowed such systems, artistic or commercial, to become at once increasingly sophisticated and part of public consciousness.

While these early works relied on prerecorded audio content, the potential of topological movement-generating music became of interest to composers. I worked with Ali Momeni and visual artist Petra Gemeinboeck in 2006 to translate notions from locative media to create a musical work, Net_Dérive, that used mobile digital devices to realize a gamelike exploration of the city in a fashion inspired by the Dérive of the radical 1960s art movement, the Situationist International. In Net_Dérive, a scarflike wearable computing harness houses two mobile phones and a GPS unitone phone acting as a sound/image capture device and the other a mobile network connected rendering device. An abstract soundscape is generated serverside based on latitude/longitude data from the location of a group of users. A constant polyrhythm shifts based on the relative proximity of the different participants, while specific coordinates are programmed to trigger voice commands instructing the person to move in certain directions. This generated soundscape is streamed over mobile broadband Universal Mobile Telecommunications System (UMTS, or $3 \mathrm{G}$ ) networks back to each of the participant's rendering device and is heard over headphones, accompanying the person's meandering walk through a city neighborhood.

Yolande Harris, in her series of GPS music pieces, questions the assumptions of locative media, notably those of permanent movement, networked connectivity, and participative collective action. In "Taking Soundings," she challenges the notion of stasis by placing a GPS unit in a fixed place. Noise in the GPS signal creates a jittery trace that is far from stationary. Harris sonifies this unstable information, poetically creating the sound of a single location on earth. "Sun Run Sun" is for single users walking with a purpose-built single-board computer with sound synthesis and location-tracking capabilities. A fixed point version of the Pure Data graphical music programming environment runs a generative sine wave patch on a single-board computer system, Satellite Sounders, built by Sukandar Kartadinata. Parsing of GPS data creates parameters mapped to synthesis parameters. This creates a direct yet complex relationship between location and the 
resulting sound, by which returning to a prior location may drive synthesis parameters similarly but does not necessarily reproduce the exact same sound.

Art Clay in "China Gates" uses secondary information in the GPS format, that of the synch pulse, to drive the timing of a distributed percussion performance. The GPS pulse becomes a metronome and conductor, creating a flashing pulse that directs percussionists to hit a gong they are carrying outdoors. A score directs their position, which in turn modulates the pulsing frequency, creating a slowly shifting acoustic ostinato of an ensemble of percussionists outside of visual contact in outdoor space.

Despite the relatively high accuracy of non-SA GPS, the temporal resolution (or sampling period) of commercial GPS units at the time of writing was about $0.5 \mathrm{~s}$, making it a relatively coarse musical control signal. Research projects of Settel at the Sociéte des Arts Technologiques (SAT) and McGill University in Montreal have used the recent arrival of ultra-high-resolution GPS devices to create responsive instruments that have the temporal resolution more commonly associated with sensor-based instruments and reactivity necessary for gestural music performance. Better location resolution and higher sampling rates allow subtle movements orientation, and small bodily variation in place to be detected to modulate musical processes, including the Audioscape virtual soundscape software.

Finally, exploiting mobile telephone's speakerphone capabilities without location sensing, two composers have created forms of acoustical ensemble for mobile phones. Greg Schiemer in his work "Mandala" arranges three performers in resonant outdoor spaces swinging mobile phones around on a string. Each phone emits a series of sine tones, and the swinging causes Doppler effects, creating shifting frequency sweeps among the three phones. Wang similarly fashioned a mobile phone orchestra, creating a conducted score in which simultaneous sounding of a group of mobile phones create cancellation and reinforcement effects, resulting in an acoustic dynamic beyond the capabilities of any single phone's speaker. Careful tuning of frequencies creates sum and difference tones that extend the frequency range of the resulting music beyond the range of the small speakers by the effect of implied fundamental.

\section{Conclusion}

Since the advent of electricity, musicians, composers, and artists have sought to tap the creative musical potential of new technologies. Inspired by the communicative possibilities afforded first by electromagnetic waves and analog circuitry and later by digital systems and networks, they seized the power of electrical, electronic, and computer technology to create expressive systems that could be considered musical instruments. The rich tradition and articulative depth of acoustical instruments set a high standard to try to match. In this way, musicians bring with them high expectations in the musical exploitation of any given technology. The 
responsiveness, resolution, and finesse of a technology translate to the often-elusive musical "feel" that is central to the successful deployment of an instrument in a performative context. This places demands on technology systems that, if solved, often contribute to engineering advances. In this way, music remains, as it always has been, the field of creative practice that directly addresses technique-whether the acoustical phenomenon of the natural overtone series or of network transmission latency.

The notion of the musical instrument, then, is a useful metaphor that defines creative contexts for technology, delineates demanding usage scenarios, and ties innovation to artistic tradition. This metaphor is not a comparative abstraction but a working model with which musicians have created functional systems and produced lasting artworks. Early in the 2oth century, electrostatic and electromagnetic field perturbations captured performer gesture with the theremin and related instruments. Electrical systems could be used to extend existing instruments, in the 1950 with the electric guitar and in the 1990s with hyperinstruments.

Musicians have the uncanny ability to appropriate and repurpose machinery and technology for expressive musical ends. This could mean taking an apparatus destined for playing back recorded music, such as the turntable, and making it an expressive instrument. This also meant taking fundamental nonmusical technologies, such as VR systems, to create live, performable instruments. From electrostatic fields to infrared beams, ultrasound sensors to bend and pressure sensors, any sensing device that could translate real-world phenomena into electrical signals was ripe material for musical instrument building in the NIME tradition. Sensing could be extremely intimate, looking at physiological effects of the performer's own body such as with bioelectrical sensors, or it could be completely external to the performer, such as with GPS signals, and still be compellingly musical and ultimately social.

With the advancement of technology come not only an extension of musical tradition, but also a questioning of it. While this chapter does not cover phenomena such as the electroacoustic studio or file-sharing technologies that have the disruptive power to put in question traditional musical roles of authorship and performance, it does look at the ways in which sensors, open-ended architectures, and programmable systems have extended the notion and very definition of the term instrument. An instrument could be a piece of hardware or a software program but could also be a reconfigurable hardware/software system. The composition could be specifically built into a system as much as a single instrument could execute a family of works. By questioning and extending traditions of the instrument, some of the basic tenets of musical instrumentality come to light-the ability for an instrument to enter into different contexts and retain its musical identity.

One of the clearest ways in which musical instruments change contexts is in different ensemble frameworks. Moving from a solo situation through chamber ensembles to orchestras places different performative and stylistic demands on an instrument. The performer's ability to navigate these different contexts with a 
given instrument is a testament to that instrument's richness. Technology musicians have taken up this call with their electronic and digital instruments, creating different groups, bands, and ensembles. This has taken on different forms-be it the integration of an instrument like the Ondes Martenot into the classical orchestra or Sensorband creating a sensor-instrument family of instruments on the chamber music model. Notions of interaction and collaborative systems from research fields like $\mathrm{HCI}$ have informed the conception and realization of shared instruments like the reacTable and other instruments using the tabletop metaphor. And, high-speed computer networks have been used not only to study ensemble performance at a distance but also to create entirely new shared musical experiences.

Music has always been a technical art, and electronic and computer music are no exception. While paradigm shifts that accompany new technologies create frontiers that redefine the artistic process, musical traditions are useful points of departure that help us to question assumptions, extend practice, and push the envelope of what is musically possible with technology. The instrument and the ensemble are two such extensible traditions. They not only extend romantic notions of the virtuoso to contemporary technological contexts but also extend musical contexts of performance to include participation and collective public action. In this way, musicians have always brought insight into the artistic application of electrical, electronics, and communications technologies. This tradition will continue to give rise to new musical instruments and musical styles.

\section{BIBLIOGRAPHY}

Attali, J. 1985. Noise: The Political Economy of Music, trans. Brian Massumi. Minneapolis: University of Minnesota Press.

Bailey, D. 1993 (originally published in 1980). Improvisation: Its Nature and Practice in Music. New York: Da Capo Press.

Barbosa, A. 2008. Displaced Soundscapes. Saarbrücken: VDM Verlag Dr. Müller. Baudrillard, J. 1983. Simulations (Foreign Agents). New York: Semiotext(e).

Chadabe, J. 1996. Electric Sound: The Past and Promise of Electronic Music. Upper Saddle River, NJ: Prentice Hall.

Chafe, C., and M. Gurevich. 2004. Network time delay and ensemble accuracy: effects of latency, asymmetry. In Proceedings of the AES 117th Conference. San Francisco: AES.

Clay, A. 2008. Inventing malleable scores: From paper to screen based scores. In Transdisciplinary Digital Art: Sound, Vision and the New Screen, ed. R. Adams,

S. Gibson, and S. M. Arisona. New York: Springer.

Collins, N. 2006. Handmade Electronic Music: The Art of Hardware Hacking. New York:

Routledge. http://www.nicolascollins.com/trombone_propelled_electronics.htm, accessed August 8, 2008.

de Laubier, S. 1998. The meta-instrument. Computer Music Journal 22(1): 25-29.

Desain, P., A. M. G. Hupse, M. G. J. Kallenberg, B. J. de Kruif, and R. S. Schaefer. 2006.

Brain-computer interfacing using frequency tagged stimuli. In Proceedings of the 3 rd 
International Brain-Computer Interface Workshop and Training Course 2006, ed.

G. R. Müller-Putz, C. Brunner, R. Leeb, R. Scherer, A. Schlögl, S. Wriessnegger, and

G. Pfurtscheller. Graz, Austria: Verlag der TU Graz.

Freed, A., R. Avizienis, and M. Wright. Beyond 0-5V: Expanding Sensor Integration

Architectures. In Conference on New Interfaces for Musical Expression (NIME-06). Paris.

Glinsky, A. 2000. Theremin: Ether Music and Espionage. Chicago: University of Illinois Press.

Harris, Y. 2007. Taking soundings: Investigating coastal navigations and orientations in sound. In Proceedings of the 4th Mobile Music Workshop. Amsterdam.

Jordà, S. 2002. FMOL: Toward user-friendly, sophisticated new musical instruments. Computer Music Journal 26(3): 23-39.

Jordà, S., G. Geiger, M. Alonso, and M. Kaltenbrunner. 2007. The reacTable: Exploring the synergy between live music performance and tabletop tangible interfaces. In Proceedings of the 1st International Conference on Tangible and Embedded Interaction 2007, pp. 139-146.

Kahn, D. 2001. Noise, Water, Meat: A History of Sound in the Arts. Cambridge: MIT Press.

Kahn, D., and G. Whitehead, eds. 1994. Wireless Imagination: Sound, Radio, and the Avant-Garde. Cambridge: MIT Press.

Kartadinata, S. 2006. The gluion: Advantages of an FPGA-based sensor interface. In Conference on New Interfaces for Musical Expression (NIME-06). Paris: NIME.

Kirisits, N., F. Behrendt, L. Gaye, and A. Tanaka. 2008. Creative Interactions: The Mobile Music Workshops 2004-2008. Di'Angewandte, Vienna.

Knapp, R. B., and H. Lusted. 1996. Controlling computers with neural signals. Scientific American 275(4): 82-87.

Lucier, A. 1995. Reflections: Interviews, Scores, Writings. Köln, Germany: MusikTexte.

Machover, T. "Hyperinstruments." http://opera.media.mit.edu/projects/hyperinstruments. html, accessed March 30, 2009.

Manning, P. 2004. Electronic and Computer Music. Oxford: Oxford University Press.

Miranda, E. R. 2006. Brain-computer music interface for composition and performance. International Journal on Disability and Human Development 5(2): 119-125.

Nakra, T. M. 2000. "Inside the conductor's jacket, analysis interpretation and musical synthesis of expressive gesture." Ph.D. thesis, MIT. http://hdl.handle.net/1721.1/9165, accessed March 30, 2009.

New Interfaces for Musical Expression (NIME). http://www.nime.org, accessed March 30, 2009.

Rosenboom, D. 1976. Biofeedback and the Arts: Results of Early Experiments. Vancouver: Aesthetic Research Centre of Canada.

Rowe, R. 2004. Machine Musicianship. Cambridge: MIT Press.

Rowe, R. 2005. Real time and unreal time: Expression in distributed performance. Journal of New Music Research 34(1): 87-96.

Schaeffer, P. 2002. Traité des objets musicaux. Paris: Seuil Editions.

Schiemer, G. 2007. Pocket Gamelan: playing Mandala 6: a demonstration. In Proceedings of the gth International Conference on Human Computer Interaction with Mobile Devices and Services: MOBILEHCI 07. New York: ACM, pp. 231-232.

Smith, H., and R. T. Dean 1997. Improvisation, Hypermedia and the Arts since 1945. Amsterdam: Harwood Academic.

Stelkens, J. 2003. peerSynth-A P2P multi-user software synthesizer with new techniques for integrating latency in real time collaboration. In Proceedings of the ICMC Singapore. USA: International Computer Music Association. 
Tanaka, A. 2000. Musical performance practice on sensor-based instruments. In Trends in Gestural Control of Music, ed. M. Wanderley and M. Battier. Paris: IRCAM, pp. 389-405. Tanaka, A. 2004. Von Telepräsenz zu Co-Erfahrung: Ein Jahrzehnt Netzwerkmusik (From telepresence to co-experience: A decade of network music). In Neue Zeitschrift für Musik, ed. G. Föllmer. Mainz: Schott Musik International.

Tanaka, A. 2008. Visceral mobile music systems. In Transdisciplinary Digital Art: Sound, Vision and the New Screen, ed. R. Adams, S. Gibson, and M. S. Arisona. New York: Springer.

Tanaka, A., and P. Gemeinboeck. 2008. "Net_Dérive: Conceiving and producing a locative media artwork." In Mobile Technologies: From Telecommunications to Media, ed. G. Goggin and L. Hjorth. New York: Routledge.

$\mathrm{Xu}$, A., W. Woszczyk, Z. Settel, B. Pennycook, R. Rowe, P. Galanter, J. Bary, G. Martin, J. Corey, and J. R. Cooperstock. 200o. Real-time streaming of multichannel audio data over Internet. Journal of the Audio Engineering Society 48: 1-22.

Wang, G., G. Essland, and H. Pentinnen. 2008 MoPhO: Do mobile phones dreams of electric orchestras? In Proceedings of the International Computer Music Conference. Belfast.

Winkler, T. 1998. Composing Interactive Music: Techniques and Ideas Using Max. Cambridge: MIT Press.

Wozniewski, M., N. Bouillot, Z. Settel, and J. R. Cooperstock. 2008. An augmented reality framework for wireless mobile performance. In Proceedings of the 5 th Mobile Music Workshop, May 13-15. Vienna, Austria.

Zimmermann, R., E. Chew, S. A. Ay, and M. Pawar. Forthcoming. Distributed musical performances: Architecture and stream management. ACM Transactions on Multimedia Computing Communications and Applications. 